\title{
Analisis Faktor-Faktor Yang Mempengaruhi Kesiapan Kerja Pada Siswa SMK Negeri 1 Sinjai
}

\author{
Muhammad Ihsan
}

SMK Negeri 1 Sinjai

\begin{abstract}
This study aims to determine the determinants of any factors that affect the readiness of work and to determine the presentation of factors that affect the readiness of work on students of SMK Negeri 1 Sinjai. This research uses descriptive explorative method. The population in this study is all students of grade 3 SMK Negeri 1 Sinjai, a number of 341 students. Samples were taken by Proportional Random Sampling technique of 200 students. The number of samples is determined 20 times the number of items / variables consisting of 20 variables. Data collection techniques and variables that are suspected to be factors that affect the readiness of work on vocational students that is learning motivation, practical experience, vocational guidance, family economic conditions, learning achievement, expectations enter the world of work, knowledge, intellectual tingkal, talents, interests , Attitudes, values, personality, physical state, appearance, temperament, skill, creativity, independence, and discipline are using questionnaires. Documentation is used to obtain student data and overview of research location. Data analysis technique used is factor analysis. The results of data analysis and discussion can be concluded that there are 7 factors that affect the readiness of work on vocational students which is the result of the reduction of 20 variables. These factors are (1) ability factor, (2) self-image factor, (3) supporting factor, (4) academic factor, (5) basic factor, (6) behavior factor, and (7) potency factor self. The biggest factor influencing the readiness of work on vocational students is a capability factor that has eigenvalue 2.665 and able to contribute $13.327 \%$ to the readiness of work on vocational students. This factor consists of learning achievement variables, intelligence level, practical experience, discipline, workplace entry, talent
\end{abstract}

Keywords: factor analysis, readiness of student work, I-E-O model, structural equation modeling

\begin{abstract}
Abstrak: Tujuan penelitian ini adalah: 1) Untuk mengetahui bagaimana hasil dari faktor-faktor yang mempengaruhi kesiapan kerja siswa SMK Negeri 1 Sinjai, 2) Untuk mengetahui hasil presentasi dari analisis faktor-faktor yang mempengaruhi kesiapan kerja pada siswa SMK Negeri 1 Sinjai, 3) Untuk mengetahui faktor-faktor apa sajakah yang mempengaruhi penerimaan kesiapan kerja siswa SMK Negeri 1 Sinjai. Penelitian ini menggunakan metode deskriptif eksploratif. Populasi dalam penelitian ini adalah seluruh siswa kelas 3 SMK Negeri 1 Sinjai sejumlah 341 siswa dan sampel sebanyak 200 siswa. Analisis data dilakukan dengan pendekatan Structural Equation Modeling (SEM), yaitu SEM berbasis covariance. Berdasarkan hasil dari analisis data yang dilakukan, diperoleh kesimpulan bahwa: 1) Pengujian variabel-variabel pada model I-E-O, yang berpengaruh pada kesiapan kerja siswa SMK Negeri 1 Sinjai, dengan menggunakan pendekatan SEM, disimpulkan model fit dengan data yang ada. 2) Faktor kemampuan memiliki nilai koefisien sebesar 5,537437. Faktor kemampuan merupakan faktor terkuat yang mempengaruhi kesiapan kerja pada siswa SMK Negeri 1 Sinjai. Faktor ini terdiri atas prestasi belajar, tingkat intelegensi, pengalaman praktek, kedisiplinan, ekspektansi masuk dunia kerja, bakat. 3) Faktor-faktor yang mempengaruhi kesiapan kerja siswa SMK Negeri 1 Sinjai, dipengaruhi oleh faktor kemampuan, faktor akademis, faktor prilaku dan potensi diri, faktor bawaan/warisan.
\end{abstract}

Kata Kunci: Analisis faktor, kesiapan kerja siswa, model I-E-O, Structural Equation Modeling (SEM). 


\section{Pendahuluan}

"Salah satu permasalahan pendidikan nasional yang hingga kini masih dihadapi bangsa Indonesia adalah rendahnya tingkat relevansi, di samping masalah mutu, pemerataan, efisiensi, dan efektivitas pendidikan" (Tirtarahardja, dkk. 2010: 229). Setiap lulusan lembaga pendidikan baik formal maupun non formal akan terjun dalam masyarakat atau dunia kerja dan menghadapi dunia nyata dengan segala tuntutan dan prasyarat yang diperlukan agar dapat memainkan perannya dengan baik. Tuntutan dan prasyarat tersebut terus mengalami perkembangan seiring dengan berkembangnya tuntutan kemajuan. Oleh karena itu, pendidikan dalam perencanaan, pengelolaan, dan pelaksanaannya harus senantiasa berorientasi pada lingkungan kerja yang selalu berubah. tidak sedikit lulusan lembaga pendidikan formal baik dari jenjang sekolah dasar, sekolah menengah perrtama, sekolah menengah atas, yang mengalami kesulitan untuk mendapatkan pekerjaan karena rendahnya kualitas dan relevansi lulusan, di samping disebabkan oleh faktor-faktor lain, seperti terbatasnya kesempatan kerja yang ada. Mismatch antara lulusan dengan dunia kerja yang terlihat dengan terus meningkatnya jumlah pengangguran tenaga terdidik tersebut merupakan cermin bahwa strategi dalam pembangunan sumber daya manusia masih perlu diperbaiki dan disempurnakan, tetapi tidak boleh terjebak pada kebijakan bahwa pendidikan semata-mata hanya untuk memenuhi tuntutan dunia kerja.

Sekolah Menengah Kejuruan (SMK) merupakan salah satu institusi pendidikan yang secara khusus bertujuan mempersiapkan peserta didik agar siap bekerja, baik bekerja secara mandiri maupun mengisi lowongan pekerjaan yang ada. Sebagaimana dinyatakan dalam Penjelasan atas UU No. 20 Tahun 2003 Tentang Sistem Pendidikan Nasional Pasal 15. Oleh karena itu SMK dituntut mampu menghasilkan lulusan dengan kompetensi standar yang diharapkan oleh dunia kerja. Tenaga kerja yang dibutuhkan adalah sumber daya manusia yang memiliki kompetensi sesuai dengan bidang pekerjaannya, memiliki daya adaptasi dan daya saing tinggi. Atas dasar itulah penyelenggaraan pendidikan di SMK senantiasa disesuaikan dengan kondisi dan kebutuhan dunia kerja.

Banyaknya variabel-variabel yang bisa mempengaruhi kesiapan kerja siswa SMK khususnya siswa SMK Negeri 1 Sinjai, maka perlu adanya pembahasan dan analisis yang mendalam tentang permasalahan tersebut, sehingga akan diperoleh beberapa faktor yang benarbenar mempengaruhi kesiapan kerja siswa.

\section{Metode Penelitian}

\subsection{Desain Penelitian}


Jenis penelitian yang digunakan dalam Penelitian ini adalah deskriptif kuantitatif. Metode penelitian faktor-faktor yang mempengaruhi kesiapan kerja pada siswa SMKN 1 Sinjai ini menggunakan jenis penelitian deskriptif eksploratif. Dengan menggunakan gabungan metode deskriptif dan eksploratif tersebut, selain mendapatkan informasi tentang kondisi kesiapan kerja pada siswa SMK secara aktual. Penelitian ini bertujuan mencari, menggali, dan menemukan faktorfaktor yang mempengaruhi kesiapan kerja pada siswa SMKN 1 Sinjai. Penelitian ini dilaksanakan di SMK Negeri 1 Sinjai.

\subsection{Tempat dan Waktu Pelaksanaan}

Penelitian ini dilakukan di SMK Negeri 1 Sinjai, Penulis merencanakan waktu penelitian ini dari bulan September 2016 sampai dengan bulan Mei 2017.

\subsection{Subjek Penelitian}

Populasi dalam penelitian ini adalah siswa kelas III SMK Negeri 1 Sinjai tahun pelajaran 2016/2017 yang memiliki program keahlian yaitu program teknik komputer dan jaringan (TKJ), tata busan, akuntansi, adm. perkantoran, pemasaran yang berjumlah 341 siswa, tersebar dalam 5 jurusan, jurusan TKJ sebanyak 81 siswa, jurusan tata busan sebanyak 19 siswa, jurusan akuntansi sebanyak 119 siswa, jurusan adm. Perkantoran sebanyak 132 siswa, dan jurusan pemasaran sebanyak 30 siswa.

Teknik pengambilan sampel dalam penelitian ini adalah proportional random sampling. Pengambilan sampel dari tiap-tiap kelas ditentukan seimbang atau sebanding dengan banyaknya jumlah siswa dalam tiap-tiap kelas tersebut dimana tiap-tiap siswa mempunyai hak yang sama untuk dipilih menjadi sampel. Banyaknya responden ditentukan sebesar 56\% dari jumlah siswa tiap-tiap kelas yang merupakan hasil perhitungan dari $\frac{200}{341}$ x $100 \%=58 \%$.

\subsection{Teknik Pengumpulan Data}

Pengumpulan data menggunakan metode penelitian kuantitatif, kualitatif. Data di kumpulkan dengan mempergunakan teknik pengumpulan data, yaitu: 1) wawancara; 2) observasi; 3) angket; dan 3) dokumentasi.

\subsection{Teknik Analisis Data}

Analisis data yang digunakan pada penelitian ini adalah analisis data dengan menggunakan teknik SEM. Teknik analisis yang digunakan adalah SEM berbasis covariance (covariance based SEM), yakni pendekatan SEM yang menggunakan tools AMOS. Data primer yang diperoleh dari pengumpulan data yang dilakukan, dimaksukkan ke dalam sebuah file excel terlwbih dahulu sebelum analisis lebih lanjut. Tools yang digunakan dalam penelitian ini untuk memasukkan data 
dalam format excel adalah Microsoft Excel 2007. Pengujian dengan menggunakan AMOS membuktikan bahwa apabila model tidak fit dengan data yang ada, maka akan dilakukan modifikasi model.

\section{Hasil dan Pembahasan}

\subsection{Kesimpulan Uji Faktor}

Berdasarkan hasil analisis faktor, dan 20 variabel yang memenuhi syarat untuk analisis lebih lanjut mengelompok menjadi 7 faktor dengan nama baru. Nama-nama faktor baru tersebut adalah (1) faktor kemampuan, (2) faktor citra diri, (3) faktor pendukung, (4) faktor akademis, (5) faktor dasar/bawaan, (6) faktor perilaku, serta (7) faktor potensi diri. Dalam hal ini 20 variabel dinyatakan diterima dengan alasan semua variabel yang telah diajukan masuk menjadi faktor baru/diterima menjadi faktor yang mempengaruhi kesiapan kerja pada siswa SMK. Lebih lanjut, faktor pertama adalah faktor yang paling kuat menentukan kesiapan kerja pada siswa SMK dengan eigenvalue 2,665 dan faktor yang paling lemah adalah faktor ke tujuh dengan eigenvalue 1,265.

\subsection{Deskripsi Data dengan Pendekatan SEM}

Analisis data dengan menggunakan AMOS, tidak memerlukan pengubahan data mentah yang telah dimasukkan ke dalam format excel menjadi matriks kovarian secara mnaual. AMOS secara otomatis akan mengubah data mentah tersebut menjadi matriks kovarian yang selanjutnya dapat dianalisis. Berikut adalah tahap-tahap analisis data yang dilakukan.

\section{1) Membuat Model SEM berdasarkan Teori}

Model SEM beserta variabel dan juga indikator yang digunakan.

\section{2) Membuat Path Diagram}

Setelah penyusunan model SEM dan juga variabel beserta indikatornya, tahapan selanjutnya adalah membuat path diagram. Path diagram yang disusun berdasarkan model yang telah dibuat tersebut dapat dilihat pada gambar 3.1 berikut :

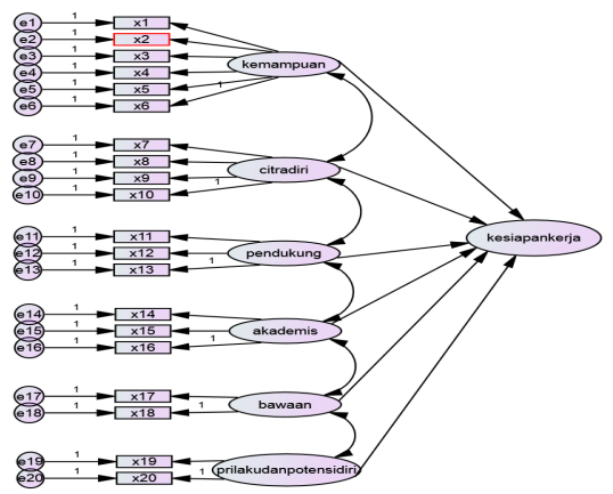


Gambar 3.1. Output Path Diagram

\section{3) Memilih Matriks dan Teknik Estimasi Model}

Secara default, NRL akan mengubah data mentah yang dimasukkan sebagai input, menjadi matriks kovarian. Matriks kovarian merupakan jenis matriks yang digunakan sebagai input untuk melakukan analisis SEM yang bertujuan untuk menguji teori. Begitu juga untuk menentukan teknik estimasi model yang direkomendasikan, MLE, AMOS secara default menggunakan teknik MLE dalam melakukan estimasi.

\section{4) Mengidentifikasi Model}

Analisis SEM hanya dapat dilakukan apabila hasil identifikasi model menunjukkan bahwa model termasuk dalam kategori over-identified. Identifikasi ini dilakukan dengan melihat nilai df dari model yang dibuat. Tabel 4.3. Adalah hasil output AMOS yang menunjukkan nilai $d f$ model sebesar 165. Hal ini mengidentifikasikan bahwa model termasuk kategori over-identified karna memiliki nilai $d f$ positif. Oleh karena itu, analisis data bisa dilanjutkan ke tahap berikutnya.

Tabel 3.1. Computation of degrees of freedom (Default model)

Number of distinct sample moments: 230

Number of distinct parameters to be estimated: 65

Degrees of freedom $(230-65): 165$

\section{5) Mengevaluasi Estimasi Model}

a. Normalitas Data

Hasil output AMOS mengenai penilaian normalitas data (dapat dilihat pada lampiran 17 hal. 153), terlihat bahwa data tidak terdistribusi normal secara multivariat, nilai c.r. data keseluruhan sebesar 10,335. Nilai ini berada di luar rentang nilai c.r. dari data yang terdistribusi normal, yaitu $-2,58$ s.d $+2,58$.

b. Multikolinearitas

Multikolinearitas ada apabila terdapat nilai korelasi antar indikator yang nilainya $\geq$ 0,9. Pada tabel nilai korelasi antar indikator pada output AMOS, terlihat tidak ada nilai korelasi antar indikator yang nilainya $\geq 0,9$. Oleh karena itu, asumsi tidak adanya multikolinearitas pada data penelitian terpenuhi. Berikut nilai korelasi antar variabel dapat dilihat pada tabel 4.4.

Tabel 3.2. Korelasi Latent Variabel

\begin{tabular}{ccccccc}
\hline & FB & FPPD & FA & FP & FK & FCD \\
\hline FB & $1,000^{*}$ & & & & & \\
FPPD & 0,317 & $1,000^{*}$ & & & & \\
FA & 0,120 & 0,123 & $1,000^{*}$ & & & \\
FP & 0,304 & 0,313 & 0,118 & $1,000^{*}$ & & $1,000^{*}$ \\
FK & 0,120 & 0,124 & 0,470 & 0,119 & 0,119 & $1,000^{*}$ \\
FCD & 0,301 & 0,310 & 0,117 & 0,297 & 0,19 \\
\hline
\end{tabular}


Keterangan:

FB: faktor bawaan

FP: faktor pendukung

FPPD: faktor prilaku dan potensi diri

FK: faktor kemampuan

FA: faktor akademis

FCD: faktor citra diri

\section{6) Uji Kelayakan Model}

a. Menguji validitas measurement model

Tahap pengujian kelayakan model terdiri dari dua tahapan pengujian, yakni pengujian measurement model dan structural model. Untuk menguji validitas measurement model, pengujian GOF dilakukan untuk mengetahui seberapa fit model dengan data penelitian yang diperoleh. Gambar 2.2. adalah path diagram yang dihasilkan setelah melakukan tahapan pemenuhan uji asumsi SEM.

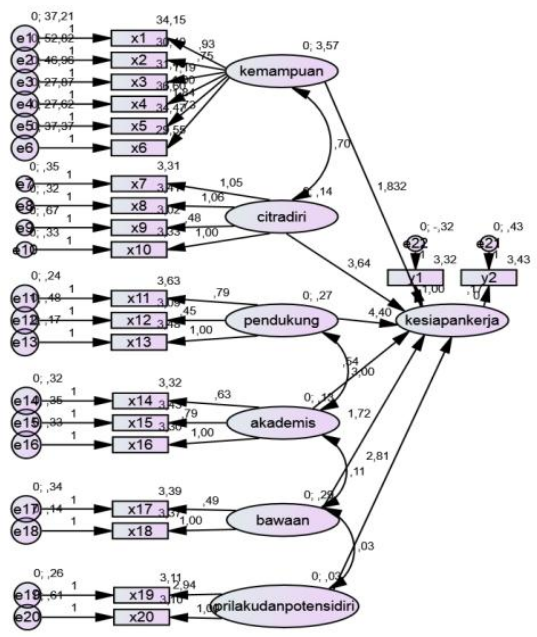

Gambar 3.2. Output Path Diagram

Berdasarkan output path diagram tersebut, dibuat rangkuman hasil pengujian GOF yang dapat dilihat pada tabel berikut:

Tabel 3.4. Hasil Pengujian GOF Model Awal

\begin{tabular}{|c|c|c|c|}
\hline $\begin{array}{l}\text { Goodness of Fit } \\
\text { (GOF) Index }\end{array}$ & Cut-off Value & $\begin{array}{c}\text { Nilai pada Model } \\
\text { Penelitian }\end{array}$ & Keterangan \\
\hline Chi-square $\left(\mathrm{x}^{2}\right)$ & $\begin{array}{c}\text { Semakin kecil, } \\
\text { Semakin baik }\end{array}$ & 84,530 & \\
\hline CMIN/DF & $<2,0$ & 1,243 & Good fit \\
\hline $\mathrm{p}$ (probabilitas) & $>0,05$ & 0,085 & Good fit \\
\hline RMSE & $<0,08$ & 0,034 & Good fit \\
\hline GFI & $>0,90$ & 0,464 & Good fit \\
\hline TLI & $>0,90$ & 0,442 & Good fit \\
\hline
\end{tabular}

Hasil pengujian GOF yang terangkum pada tabel 4.6., terbukti bahwa model hasil modifikasi fit dengan data yang ada. Oleh karena itu, pengujian hipotesis bisa dilakukan. Uji hipotesis dilakukan dengan melihat nilai C.R. (critical ratio) yang terdapat pada tabel output AMOS mengenai regression weights.

Tabel 3.5. Regression Weihts 


\begin{tabular}{lrrrrl}
\hline & Estimate & S.E. & C.R. & P & Label \\
\hline kemampuan & 2,3762865 & 1,7184478 & 1,8328098 &, 1667232 & par_43 \\
citradiri &, 1552367 &, 0425421 & 3,6490159 & $* * *$ & par_44 \\
pendukung &, 2514131 &, 0570166 & 4,4094748 & $* * *$ & par_45 \\
akademis &, 0906261 &, 0301770 & 3,0031528 &, 0026720 & par_46 \\
prilakudanpotensidiri &, 0755368 &, 0437305 & 1,7273270 &, 0841090 & par_47 \\
bawaan &, 3508299 &, 1245762 & 2,8161871 &, 0048597 & par_48 \\
\hline
\end{tabular}

Pengujian hipotesis dilakukan dengan membandingkan nilai C.R. pada Tabel 4.7. dengan nilai kritisnya yang identik dengan nilai $t$ hitung, yakni 1,65 pada tingkat signifikansi 5\%. Jika nilai C.R. lebih besar daripada nilai kritisnya dengan tingkat signifikansi $\mathrm{p}<0,05$, maka hipotesis yang diajukan diterima. Tetapi, apabila nilai C.R. belum dapat mencapai nilai kritisnya pada tingkat signifikansi $\mathrm{p}>0,05$, maka hipotesis yang diajukan ditolak.

Berikut adalah pembahasan setiap uji hipotesis berdasarkan hasil pengujian yang terangkum pada tabel 3.6.:

1. Faktor kemampuan berpengaruh terhadap kesiapan kerja

Hasil output AMOS yang terlihat pada Tabel 3.6, diketahui nilai C.R. sebesar 1,832. Nilai ini melebihi nilai kritisnya, yaitu 1,65. Oleh karena itu, disimpulkan bahwa hipotesis ini diterima. Hasil ini menunjukkan bahwa faktor kemampuan memiliki pengaruh signifikan terhadap kesiapan kerja dengan nilai koefisin sebesar 2,37.

2. Faktor citra diri berpengaruh terhadap keiapan kerja

Terlihat pada Tabel 3.6. bahwa nilai C.R. sebesar 3,64. Nilai ini melebihi nilai kritisnya, yaitu 1,65. Oleh karena itu, disimpulkan bahwa hipotesis ini juga diterima. Hasil ini menunjukkan bahwa faktor citra diri memiliki pengaruh signifikan terhadap kesiapan kerja dengan nilai koefisien sebesar 0,15 .

3. Faktor pendukung berpengaruh terhadap kesiapan kerja

Output AMOS yang terlihat pada Tabel 3.6., diketahui nilai C.R. sebesar 4,409. Nilai ini melebihi nilai kritisnya, yaitu 1,65. Oleh karena itu, disimpulkan bahwa hipotesis ini diterima. Hasil ini menunjukkan bahwa faktor pendukung memiliki pengaruh signifikan terhadap keiapan kerja dengan nilai koefisien sebesar 0,25.

4. Faktor akademis berpengaruh terhadap kesiapan kerja

Output AMOS yang terlihat pada Tabel 3.6., diketahui nilai C.R. sebesar 3,003. Nilai ini melebihi nilai kritisnya, yaitu 1,65. Oleh karena itu , disimpulkan bahwa hipotesis ini diterima. Hasil ini menunjukkan bahwa faktor akademis memiliki pengaruh yang signifikan terhadap kesiapan kerja dengan nilai koefisien sebesar 0,09.

5. Faktor prilaku dan potensi diri berpengaruh terhadap kesiapan kerja

Output AMOS yang terlihat pada Tabel 3.6. diketahui nilai C.R. sebesar 1,727. Nilai ini melebihi nilai kritisnya yaitu 1,65. Oleh karena itu, disimpulkan bahwa hipotesis ini diterima. Hal ini menunjukkan bahwa faktor prilaku dan potensi diri memiliki pengaruh yang signifikan terhadap kesiapan kerja dengan nilai koefisien 0,07. 
6. Faktor bawaan berpengaruh terhadap kesiapan kerja

Output AMOS yang terlihat pada Tabel 3.6. diketahui nilai C.R. sebesar 0,124. Nilai ini lebih kecil daripada nilai kritisnya yaitu 1,65. Oleh karena itu, disimpulkan bahwa hipotesis ini ditolak. Hasil ini menunjukkan bahwa faktor bawaan tidak memiliki pengaruh yang signifikan terhadap kesiapan kerja dengan nilai koefisien 0,35.

Berdasarkan penjelasan diatas dapat disimpulkan bahwa faktor kemampuan memiliki nilai koefisien tertinggi dibandingkan dengan faktor yang lain. Nilai koefisien yang dimiliki sebesar 2,37. Faktor kemampuan merupakan prediktor terkuat yang mempengaruhi kesiapan kerja. Hal ini sesuai dengan penelitian Ariyani (2010) yang menyatakan bahwa faktor kemampuan merupakan prediktor terkuat dalam model I-E-O.

Tabel 3.7. Uji Structural Model

\begin{tabular}{lllcc}
\hline & & & \multicolumn{1}{c}{ C.R. } & Keterangan \\
\hline kesiapankerja & $<---$ & prilakudanpotensidiri & 5,262942 & Signifikan \\
kesiapankerja & $<---$ & bawaan & 3,799756 & Signifikan \\
kesiapankerja & $<---$ & akademis & 2,768894 & Signifikan \\
kesiapankerja & $<---$ & pendukung & 0,616655 & Tidak signifikan \\
kesiapankerja & $<---$ & kemampuan & 5,537437 & Signifikan \\
kesiapankerja & $<---$ & citradiri & 1,504453 & Tidak signifikan \\
\hline
\end{tabular}

Berdasarkan hasil uji structural model di atas dapat disimpulkan:

1. Hipotesis bahwa faktor perilaku dan potensi diri berpengaruh pada kesiapan kerja, terbukti signifikan dengan koefisien sebesar 5,926294. Nilai ini lebih besar dari nilai kritisnya yaitu 1,65. Oleh karena itu, hipotesis ini diterima.

2. Hipotesis bahwa faktor bawaan berpengaruh pada kesiapan kerja, terbukti signifikan dengan koefisien sebesar 3, 799756. Nilai ini lebih besar dari nilai kritisnya yaitu 1,65. Oleh karena itu, hipotesis diterima

3. Hipotesis bahwa faktor akademis berpengaruh pada kesiapan kerja, terbukti signifikan dengan koefisien sebesar 2, 768894. Nilai ini lebih besar dari nilai kritisnya yaitu 1,65. Oleh karena itu, hipotesis diterima.

4. Hipotesis bahwa faktor pendukung berpengaruh pada kesiapan kerja ditolak, terbukti tidak signifikan dengan koefisien sebesar 0,616655. Nilai ini lebih kecil dari nilai kritisnya yaitu 1,65. Oleh karena itu, hipotesis di tolak.

5. Hipotesis bahwa faktor kemampuan berpengaruh pada kesiapan kerja, terbukti signifikan dengan koefisien sebesar 5,537437. Nilai ini lebih besar dari nilai kritisnya yaitu 1,65. Oleh karena itu, hipotesis diterima. Faktor kemampuan merupakan prediktor yang terkuat. Hal ini sejalan dengan penelitian yang dilakukan sebelumnya oleh Ariyani (2010). Yang mengemukakan bahwa faktor kemampuan meruapakan faktor terkuat yang mempengaruhi kesiapan mahasiswa. 
6. Hipotesis bahwa faktor citra diri berpengaruh pada kesiapan kerja ditolak, terbukti tidak signifikan dengan koefisien sebesar 1,504453. Nilai ini lebih kecil dari nilai kritisnya yaitu 1,65 . Oleh karena itu, hipotesis di tolak.

\section{Simpulan dan Saran}

\subsection{Kesimpulan}

1. Hasil dari tahap analisis instrumen dengan Exploratory Factor Analysis (EFA), diperoleh 7 faktor yang mempengaruhi kesiapan kerja pada siswa SMK. Ketujuh faktor tersebut adalah (1) faktor kemampuan terdiri atas variabel keterampilan, pengalaman praktik, dan kreativitas, (2) faktor citra diri terdiri atas variabel pengetahuan, penampilan diri, dan temperamen, (3) faktor pendukung terdiri atas variabel informasi pekerjaan, kondisi ekonomi keluarga, dan bimbingan vokasional, (4) faktor akademis terdiri atas variabel kedisiplinan, dan prestasi belajar, (5) faktor dasar / bawaan terdiri atas variabel nilai-nilai, keadaan fisik, dan bakat, (6) faktor perilaku terdiri atas variabel sikap, kemandirian, dan minat, dan (7) faktor cita-cita dan potensi diri terdiri atas variabel ekspektasi masuk dunia kerja, dan tingkat intelegensi. Hasil dari ketujuh faktor dianalisis dengan menggunakan AMOS, yaitu dengan menggunakan model I-E-O. Model tersebut digunakan untuk menguji apakah model I-E-O tepat digunakan untuk mengetahui pola adopsi kesiapan kerja siswa SMK Negeri 1 Sinjai, selain menguji teori, penelitian ini juga dilakukan untuk menguji variabel-variabel pada model I-E-O, yang berpengaruh pada kesiapan kerja siswa SMK Negeri 1 Sinjai. Analisis data dilakukan dengan pendekatan Structural Equation Modeling (SEM), yaitu SEM berbasis covariance. Ada beberapa macam uji kelayakan model yang dilakukan untuk menguji GOF, diantaranya adalah chi-square, GFI, RMSR, RMSR, RMSEA, NFI, CFI, TLI, dan RNI.

2. Faktor kemampuan memiliki nilai koefisien sebesar 5,537437. Faktor kemampuan merupakan faktor terkuat yang mempengaruhi kesiapan kerja siswa SMK Negeri 1 Sinjai. Faktor ini terdiri atas prestasi belajar, tingkat intelegensi, pengalaman praktek, kedisiplinan, ekspektansi masuk dunia kerja, bakat. Hal ini sesuai dengan penelitian Ariyani (2010) yang menyatakan bahwa faktor kemampuan merupakan prediktor terkuat dalam model I-E-O.

3. Dari enam hipotesis yang diajukan, empat hipotesis dinyatakan diterima, dan dua hipotesis ditolak. Berdasarkan hipotesis yang didukung, yaitu H1, H3, H5, H6, dapat disimpulkan bahwa faktor-faktor yang mempengaruhi kesiapan kerja pada siswa SMK Negeri 1 Sinjai adalah faktor kemampuan, faktor akademis, faktor prilaku dan potensi

diri, faktor bawaan, warisan. Sementara dua faktor yang tidak didukung yang menunjukkan bahwa penerimaan pada kesiapan kerja siswa SMK Negeri 1 Sinjai tidak memiliki pengaruh signifikan yang mendorong kesiapan kerja. 


\subsection{Saran}

Berdasarkan kesimpulan dan implikasi di atas, dapat dikemukakan saran sebagai berikut:

\section{Bagi Siswa}

a. Siswa diharapkan terus meningkatkan kemampuan akademis baik secara teori maupun praktek, dengan belajar dan berlatih secara sungguh-sungguh terutama pada waktu praktek kerja sehingga akan memiliki tingkat keterampilan dan pengalaman kerja yang cukup.

b. Senantiasa menampilkan citra diri yang positif baik dalam bertutur kata/berkomunikasi, berpenampilan maupun dalam berperilaku.

c. Mengeksplorasi potensi diri secara maksimal agar dapat berkembang melalui kegiatan/pelatihan yang diadakan pihak sekolah.

\section{Bagi Guru}

a. Guru diharapkan mampu melaksanakan proses pembelajaran secara optimal dengan memanfaatkan sarana/media yang ada serta dengan metode yang tepat.

b. Guru diharapkan mampu memberikan dasar pengetahuan, keterampilan dan sikap kerja yang kuat agar mempermudah siswa untuk menyesuaikan diri ketika melaksanakan praktek kerja di dunia usaha/industri.

c. Diharapkan para guru dapat meningkatkan kinerjanya sehingga menjadi tenaga pendidik yang mampu menyesuaikan diri dengan perkembangan dan tuntutan dunia kerja.

\section{Bagi Sekolah}

a. Sekolah diharapkan mampu menyediakan sarana dan prasarana pembelajaran serta mengoptimalkan pemanfaatannya untuk mendukung proses pembelajaran dalam usaha mencapai tujuan.

b. Untuk memperlancar proses pembelajaran terutama untuk pelatihan di dunia usaha/industri sekolah diharapkan mampu menjalin hubungan sebanyak-banyaknya dengan dunia usaha/ industri, sehingga akan mempermudah penempatan siswa dalam praktek kerja yang sesuai dengan bidang keahliannya.

\section{Daftar Pustaka}

Awaluddin. A. 2014. Pengaruh Pengalaman Praktik, Prestasi Belajar Dasar Kejuruan dan Dukungan Orang Tua terhadap Kesiapan Kerja Siwa Smk. UNY: Jurnal Pendidikan Vokasi. Vol.4, No. 2.

Elis, W. 2016. Pengaruh Motivasi Belajar Siswa terhadap Hasil Belajar Matematika Siswa di SD Angkasa 10 Halim Perdana Kusuma. Jakarta Timur: Jurnal Pendidikan Matematika STKIP Garut, Vol. 8, No. 3 
Hamdu Ghullam, dkk. 2011. Pengaruh Motivasi Belajar Siswa Terhadap Prestasi Belajar IPA di Sekolah dasar. UPI: Jurnal Penelitian Pendidikan Vol 12, No. 1.2011

Sukiyasa, dkk. 2013. Pengaruh Media Animasi terhadap Hasil Belajar dan Motivasi Belajar Siswa Materi sitem Kelistrikan Otomotif. UNY: Jurnal Pendidikan Vokasi, Vol. 3, No. 1.

Sugihartono. 1991. Aspirasi Siswa terhadap Pekerjaan dan Prestasi Akademik Kaitannya dengan Kesiapan Memasuki Dunia Kerja pada Siswa Sekolah Kejuruan di Daerah Istimewa Yogyakarta. Laporan Penelitian. Yogyakarta: IKIPYogyakarta.

Sugihartono, dkk. 2012. Psikologi Pendidikan. Yogyakarta: UNY Press

Sitti Mania. 2013. Metode Penelitian Pendidikan dan Sosial. Makassar: Alauddin University Press 